\title{
Erzincan Yöresinde Üretilen Tulum Peynirlerinin Benzoik Asit, Sorbik Asit ve Ă̆ır Metal İçeriği Yönünden İncelenmesi
}

\author{
Yalçın EROĞLU®D
}

Erzincan Binali Yıldırım Üniversitesi Eczacılık Fakültesi Temel Eczacılık Bilimleri Bölümü, 24100, Erzincan

Geliş / Received: 06/12/2019, Kabul / Accepted: 27/12/2019

\begin{abstract}
Öz
Erzincan tulum peynirinde standart bir üretim tekniğinin olmaması, piyasada farklı kalite ve lezzette peynirlerin olmasına sebep olmaktadır. Bu peynir çeşidine özgü niteliklerin bilimsel yöntemlerle incelenerek, standart peynirin belirlenmesi ve kantitatif analize uygunluğu araştırılmıştır. Artan üretim ihtiyacından dolayı tulum peyniri üretim aşamalarında yabancı madde kullanımı ihtimali ortaya çıkmaktadır. Eğer yabancı madde kullanımı varsa bunlardan öne çıkanı oldukça düşük maliyetinden dolayı nişastadır. Ayrıca başka yabancı madde varsa bunların tespiti yapılmıştır. Bu çalışmada çeşitli spektroskopik yöntemler kullanılarak Erzincan yöresinde ticari amaçla üretilen ve piyasaya sürülen tulum peynirlerinin standartlara uyup uymadığı kontrol edilmiştir.
\end{abstract}

Anahtar Kelimeler: Tulum peyniri, Raman spektroskopisi, Nişasta, Benzoik Asit, Ağır metal

\section{Investigation of Tulum Cheese Produced in Erzincan Region in Terms of Benzoic Acid, Sorbic Acid and Heavy Metal Content}

\begin{abstract}
The fact that there is no standard production technique in Erzincan Tulum cheese leads to different quality and delicious cheeses in the market. The characteristics of this type of cheese was examined by scientific methods, the determination of standard cheese and its suitability to quantitative analysis were investigated. Due to the increased production need, the possibility of using foreign materials in the production stages of Tulum cheese emerges. If there is foreign substance use, it is starch because of its low cost. If there are other foreign substances, they were determined. In this study, it was checked whether the Tulum cheeses produced for commercial purposes and placed on the market in Erzincan region by using various spectroscopic methods conform to the standards.
\end{abstract}

Keywords: Tulum cheese, Raman spectroscopy, Starch, Benzoic Acid, Heavy Metals

\section{Giriş}

Ülkemizde peynir üretiminde kullanılan gerek sütün çeşidi ve gerekse uygulanan işlemlere bağlı olarak 130'dan fazla peynir çeşidi bulunmaktadır. Bu peynir çeşitliliği içerisinde tulum peyniri en fazla üretilenler arasında yer almaktadır (Tekinşen OC., Tekinşen KK.). Erzincan tulum peyniri, Orta Anadolu ve bat1 da Erzincan tulum peyniri, ülkenin doğusunda ise Şavak tulum peyniri olarak bilinen kuru tipteki bir peynirdir. Halk tarafindan tüketilen Erzincan tulum peyniri genellikle küçük çaplı işletmelerde hijyenik olmayan şartlarda üretilmekte ve halk sağlığ 1 açısından tehlike arz etmektedir. Erzincan tulum peyniri başlarda esas üretimi gerçekleştiren ve Tunceli civarında yerleşim gösteren Şavak aşiretinin ismiyle anılan bu peynir, günümüzde ticaretinin 
Erzincan'da ön plana çıkması nedeniyle ülke genelinde Erzincan tulum peyniri olarak tanınmaktadır. Bu peynir yöresel olarak genellikle Tunceli, Erzincan, Bingöl, Elazığ'daki yüksek rakımlı yaylalarda yaz bahar aylarında bölge halkı tarafından yapılmaktadır. Erzincan tulum peynirinin üretiminde genellikle Akkaraman koyunlarının sütü tercih edilmektedir. Erzincan İl Gıda Tarım ve Hayvancilık Müdürlüğü Erzincan genelinde tulum peynirinin y1llık üretiminin 4-5 bin ton civarında olduğunu, ticari hacminin ise yaklaşık 90-100 milyon lira olduğunu bildirmektedir (Bostan K.)

Erzincan peynirciler sitesinde bulunan satış noktalarında üreticiler genellikle kendi mamullerini pazarlamaktadır. Ayrıca bazı üreticiler de şehrin çeşitli noktalarında satış noktası bulundurmaktadır.

Artan üretim ihtiyacindan dolayı tulum peyniri üretim aşamalarında yabancı madde kullanımı ihtimali ortaya çıkmaktadır. Eğer yabanc1 madde kullanımı varsa bunlardan öne çıkanı oldukça düşük maliyetinden dolayı nişastadır. Ayrıca başka yabancı madde varsa bunların tespiti yapılacaktır. $\mathrm{Bu}$ çalışmada çeşitli spektroskopik yöntemler kullanılarak Erzincan yöresinde ticari amaçla üretilen ve piyasaya sürülen tulum peynirlerinin standartlara uyup uymadığı kontrol edilecektir.

\section{Materyal ve Metot}

Materyal olarak Erzincan ilinin çeşitli yerlerinde bulunan ve üretici firmaları farklı 8 satış noktasından alınan tulum peyniri örnekleri kullanılmıştır. Numuneler ayrı ayrı paketlenip buzdolabında muhafaza edilerek laboratuvar ortamına alınmıştır.

\subsection{Tulum Peyniri Örneklerinin Hazırlanması}

Tulum Peyniri örneklerinin hazırlanmasında Milestone mikrodalga bozundurma sistemi kullanılmıştır. Cihaz kataloğundaki yönteme göre $0.5 \mathrm{~g}$ numune tartılarak mikrodalga bozundurma kabına alınır ve üzerine uygun saflıktaki $6 \mathrm{~mL}$ nitrik asit ve $2 \mathrm{~mL}$ hidrojen peroksit eklenir. Daha sonra, Tablo 1'de verilen iki basamaklı sıcaklık programı kullanılarak örnekler yakılır. Bu işlemden sonra örnekler $50 \mathrm{~mL}$ 'lik balon joje ye transfer edilerek hacmine ultra saf su ile tamamlanmıştır (Öztürk B. ve ark.).

Tablo 1. Sicaklık kontrollü mikrodalga bozundurma programı

\begin{tabular}{llll} 
Adımlar & Sicaklık Değişimi & Artış hızı & Bekleme Süresi \\
\hline Adım & $20^{\prime}$ den $120^{\circ} C^{\prime} y e$ & 10 & $5 d k$ \\
Adım & $120^{\prime \prime}$ dan $180^{\circ} C^{\prime} y e$ & 4 & $5 d k$
\end{tabular}




\subsection{ICP-MS ölçümleri}

ICP MS ile yapılan ölçümlerde, plasma gücü $1550 \mathrm{~W}$ olarak ayarlanmıştır ve diğer ölçüm parametreleri Tablo-2'de verilmiştir. Lens parametreleri pik şekli ve maksimum sinyal elde edilmek üzere otomatik olarak optimize edilmiştir (Ekici H. ve ark.).

Tablo 2. ICP MS sisteminde kullanılan ölçüm parametreleri

\begin{tabular}{ll} 
Parametre & Kullanılan Değer \\
\hline Ar akış hızı (L/min) & 15 \\
He akış hızı (mL/min) & 4 \\
Taşıyıcı gaz akış hızı (mL/min) & 1.1 \\
Örnekleme Derinliği (mm) & 10 \\
İç standart & Sc
\end{tabular}

\subsection{HPLC Örnek Hazırlanması}

100 mL'lik balon jojeye $5 \mathrm{~g}(5 \mathrm{~mL})$ homojenize edilmiş örnek alınır. Örnek üzerine $\mathrm{MeOH}-\mathrm{Saf}$ su $(35: 65)$ karışımından 15-20 mL ilave edilir. 15-30 saniye çalkalanır ve yaklaşık $60 \mathrm{~mL} \mathrm{MeOH-Saf} \mathrm{su}$ (35:65) karışımı ilave edilir. Tekrar çalkalanır ve soğuyup hacim sabitlenince $\mathrm{MeOH}-\mathrm{Saf}$ su (35:65) karışımı ile çizgisine tamamlanır. 20-30 $\mathrm{mL}$ süspansiyon kaba filtre kağıdından süzülür ve ilk $10 \mathrm{~mL}$ süzüntü atılır. Süzüntü enjektöre alınır ve $0.45 \mu \mathrm{m}$ filtreden viallere süzülür. Kromatografik sisteme enjekte edilir.

\subsection{HPLC Analizi}

HPLC analizlerinde $5 \mu \mathrm{m}$ partikül çapına sahip 250x4.6 mm Zorbax C-18 kolon sıcaklık kontrol edilmeksizin kullanılmıştır. Ölçümler, izokritik koşullarda (Metanol : Asetat tamponu, 35:65, v/v) $0.8 \mathrm{~mL} / \mathrm{dk}$ akış hızında gerçekleştirilmiştir. Dedeksiyon dalga boyları benzoik asit için 235 ve sorbik asit için 254 nmye ayarlanmıştır.enjeksiyon

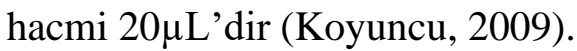

\subsection{Raman Ölçümleri}

Birkaç miligram numune küçük bir alüminyum numune kabına yerleştirildi, $100 \mathrm{~mW}$ gücünde bir lazer 1şı ğ verildi ve numuneye odaklandı ve saçılan radyasyon $180{ }^{\circ}$ 'de toplandi. Her bir spektrum için ortalama 1024 tarama yapıld1. 3500-400 $\mathrm{cm}^{-1}$ aralığında $4 \mathrm{~cm}^{-1}$ çözünürlükte ölçümler gerçekleştirildi (P. H. R. Júnior ve ark.).

\section{6 İyot ile Nişasta Aranması}

İyot çözeltisi ile nişastanın mavi renk oluşturduğu bilinmektedir. Bir deney tüpü içerisine nişasta standardından eklenir ve üzerine iyot çözeltisi ilave edilir ve oluşan renk gözlemlenir. Benzer şekilde içinde peynir numuneleri üzerine iyot çözeltisi eklenerek renk değişimi gözlenir ve standart tüple karşılaştırılır. 


\section{Bulgular}

Tulum peyniri örneklerinde koruyucu madde, ağır metal ve yabancı madde olarak nişasta aranmasına yönelik olarak spektroskopik-kimyasal tanıma reaksiyonu ile karakterizasyonları gerçekleștirilmiștir. Materyallerin koruyucu madde ve ağır metal tayinlerine yönelik veriler Tablo-3'de verilmiştir.

Tablo -3. Sekiz farklı numunenin 3 farklı ölçümüne ait veriler

\begin{tabular}{|c|c|c|c|c|c|c|c|c|c|}
\hline & $\begin{array}{c}\text { Limit } \\
\text { Değerleri* }\end{array}$ & 1 & 2 & 3 & 4 & 5 & 6 & 7 & 8 \\
\hline $\begin{array}{c}\text { Benzoik } \\
\text { asit(mg/kg) }\end{array}$ & 40 & $28,4 \pm 0,4$ & $37,9 \pm 0,9$ & $51,4 \pm 0,1$ & $1,9 \pm 0,2$ & $16,9 \pm 0,4$ & $28,4 \pm 0,4$ & $14,2 \pm 0,1$ & $60,4 \pm 0,1$ \\
\hline $\begin{array}{c}\text { Sorbik asit } \\
(\mathbf{m g} / \mathbf{k g})\end{array}$ & 1000 & $<\mathrm{BAS}^{*}$ & $<\mathrm{BAS}$ & $<\mathrm{BAS}$ & $<\mathrm{BAS}$ & $<$ BAS & $<$ BAS & $<$ BAS & $<$ BAS \\
\hline $\begin{array}{r}\text { Arsenik } \\
(\mu \mathrm{g} / \mathrm{kg})\end{array}$ & - & $10,7 \pm 0,4$ & $25,1 \pm 0,2$ & $16,4 \pm 0,1$ & $37,6 \pm 0,1$ & $20,4 \pm 0,1$ & $20,4 \pm 0,1$ & $51,9 \pm 0,2$ & $32,4 \pm 0,1$ \\
\hline $\begin{array}{c}\text { Civa } \\
(\mu \mathrm{g} / \mathrm{kg})\end{array}$ & 30 & $<$ BAS & $<$ BAS & $11,4 \pm 0,1$ & $7,6 \pm 0,1$ & $<$ BAS & $5,4 \pm 0,1$ & $9,8 \pm 0,2$ & $<$ BAS \\
\hline$\underset{(\mu \mathrm{g} / \mathrm{kg})}{\text { Kadmiyum }}$ & - & $<$ BAS & $<\mathrm{BAS}$ & $7,1 \pm 0,1$ & $10,1 \pm 0,1$ & $<$ BAS & $14,4 \pm 0,1$ & $8,8 \pm 0,1$ & $6,4 \pm 0,1$ \\
\hline $\begin{array}{c}\text { Kurşun } \\
(\mu \mathrm{g} / \mathrm{kg})\end{array}$ & 300 & $14,2 \pm 0,1$ & $9,1 \pm 0,1$ & $23,1 \pm 0,1$ & $18,1 \pm 0,1$ & $13,3 \pm 0,1$ & $36,4 \pm 0,5$ & $22,1 \pm 0,1$ & $58,8 \pm 0,1$ \\
\hline
\end{tabular}

- www.tulumpeyniri.gen.tr/turk-gida-kodeksi-peynir-tebligi/erişimi. *Belirtme Alt Sınırı (BAS)

Sekiz farklı numunenin ölçümlerinden oluşturulan sütun grafiği Şekil 1'de verilmiştir.

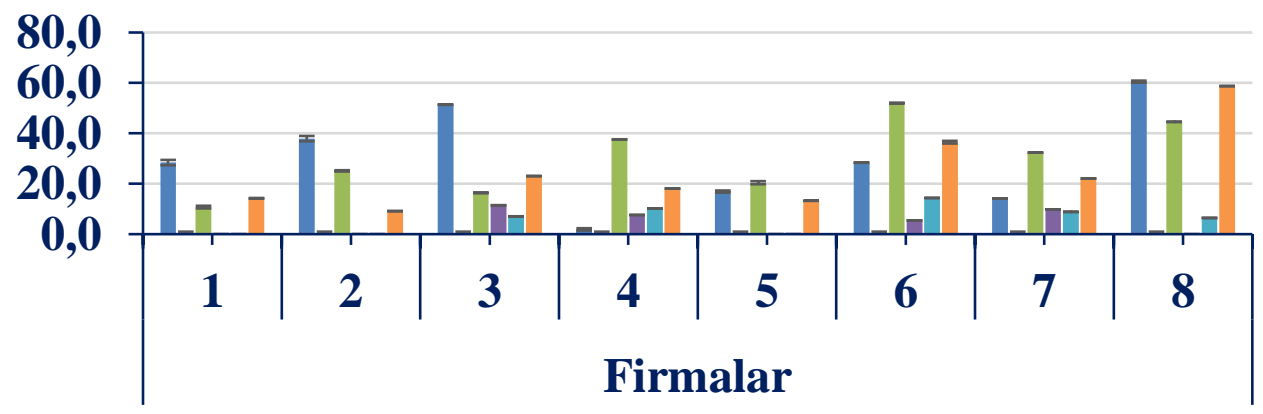

Benzoik asit $(\mathrm{mg} / \mathrm{kg}) \quad \square$ Sorbik asit $(\mathrm{mg} / \mathrm{kg}) \quad \square$ Arsenik $(\mu \mathrm{g} / \mathrm{kg})$

Şekil-1. Sekiz farklı numunenin 3 farklı ölçümüne ait veriler 
Tulum peyniri numunelerinden raman saçılması ile nişasta aranması sonucunda oluşan spektrumlar Şekil2'deki gibi izlenmiştir. Nişasta molekülüne ait 1155, 1127, 1110, 1084 ve $1053 \mathrm{~cm}^{-1}$ dalga sayısındaki Raman pikleri (Mutungi ve ark.) bu bölgedeki spektrumda gürültünün fazla olması nedeniyle sinyal/gürültü oranı 10 'un altında kaldığından dolayı kantitatif tayinde kullanılamamıştır.

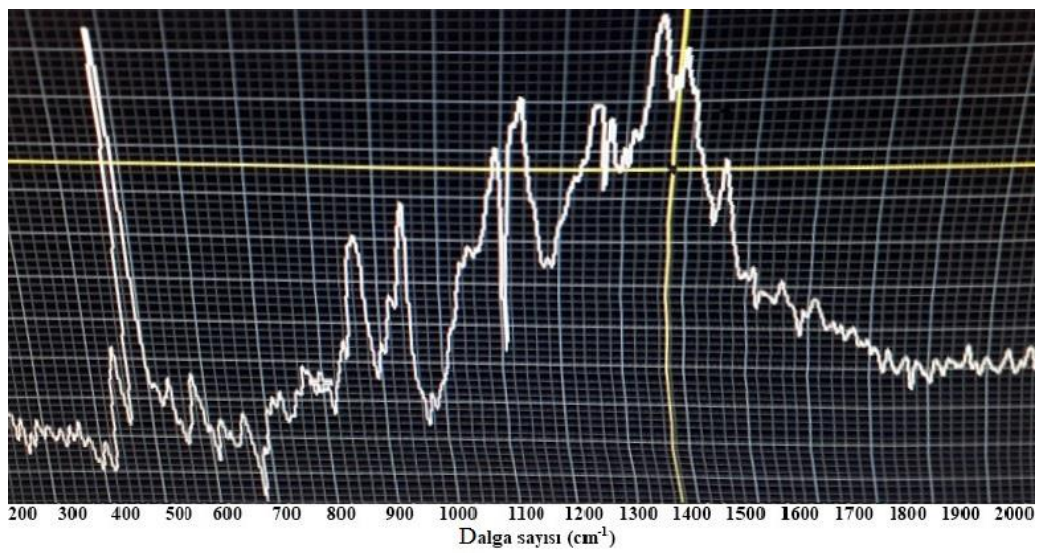

Şekil-2. Peynir numunelerinin raman saçılması ile oluşturduğu pikler

Deney tüpüne primer saflıkta nişasta konularak iyot çözeltisi damlatıldı ve standart çözelti hazırlandı, mavi renk oluşumu gözlendi. Diğer deney tüplerine peynir numuneleri alınarak çözündü ve iyot çözeltisi damlatıldığında mavi renk oluşmadığı görüldü ve kalitatif olarak nişasta tespit edilmedi. Tulum peyniri numunelerinde iyot testi ile nişasta tespitine yönelik deney tüplerinde gözlenen renkler Şekil-3'de verilmiştir.

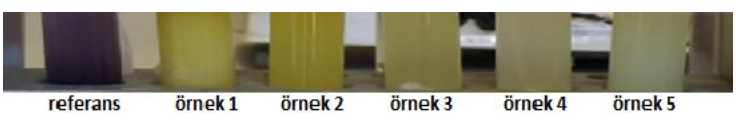

Şekil-3. Peynir numunelerinde iyot testi ile nişasta aranması

\section{Sonuç ve Tartışma}

Tulum peyniri numunelerinden alınan sonuçlara göre cıva miktarı en yüksek olan 3 nolu üreticinin $(11,46 \mu \mathrm{g} / \mathrm{kg})$ en yüksek sonuca sahip olmasına rağmen Türk Gıda Kodeksine uygun sonuçlar çıkmaktadır.
Tespit edilen kurşun düzeyleri sonucu 8 nolu üreticiden alınan numunede (58,76 $\mu \mathrm{g} / \mathrm{kg}$ ) en yüksek değer görülmüştür ancak bu değer Türk Gida Kodeksine göre uygundur $(0,3 \mathrm{mg} / \mathrm{kg})$. Numunelerdeki benzoik asit miktarı 1,9 ile $60,4 \mathrm{mg} / \mathrm{kg}$ aralığında tespit edilmiş olup sorbik asite rastlanılmamıştır. Arsenik miktarı 10,73$51,87 \mu \mathrm{g} / \mathrm{kg}$ aralığında, kadmiyum miktarı ise üç numunede tespit edilememiş olup diğerlerinde 7,06-14,36 $\mu \mathrm{g} / \mathrm{kg}$ seviyelerinde ölçülmüştür. Numunelere uygulanan iyot testi sonucunda 8 numunenin hiç birinde nişasta tespiti yapılmamıştır. Tulum peyniri üretim aşamalarında görüldüğü üzere hijyen son derece önemli bir husustur. Halk sağlı̆̆ını tehdit eden üretim tekniği, taşıma koşulları ve hayvan besleme şekilleri tek tek kontrol edilmelidir. Ağır metallere peynirde yer verecek uygulamalardan kaçınılmalıdır. İmalathaneler kontrole tabi tutulmalı, paketleme koşulları incelenmelidir. Raman spektroskopisi ile nişasta tespitine yönelik çalışmalarda piklerin kantitatif olarak 
çalışmaya imkân vermediği öngörülmüştür. Ayrıca üreticilerden alınan örnekler oldukça kısıtlıdır. Özellikle nişasta tayini yapılacağı söylendiğinde üreticiler numune vermekten kaçınmaktadırlar. Numune toplamanın zorluğu göz önüne alındığına geniş kapsamlı proje desteğiyle analizler yapmak daha anlamlı olacaktır. Süt ürünleri sıklıkla tüketilmesi nedeniyle, ağır metal içermesi durumunda, çeşitli hastalıkların ve lezyonların yaygınlığının nedeni olabilir. Besin zincirine ve dolayısıyla süte de kontamine olan ağır metallerin özellikle endüstri ve tarımdan kaynaklandığı anlaşılmaktadır. Bu nedenle, bu maddelerin insanlara olumsuz etkilerinden kaçınmak ve süt ve ürünlerinin kalitesini artırmak için süt üretilen alanların çevre kirliliğinin önlenmesi önemlidir. Gıda ambalaj1 olarak kullanılan malzemeler, insan sağlığı açısından zararsız olmalıdır. Genel halk sağlı̆̆ açısından da çevre kirliliği hususunda etkin duyarlılığa ihtiyaç vardır.

\section{Kaynaklar}

Bostan K. 1991 Değişik Ambalajlar İçinde Bulunan Tulum Peynirlerinin Duyusal, Kimyasal ve Mikrobiyolojik Özellikleri, "Her Yönüyle Peynir". II. Baskı, Tekirdağ: Tekirdağ Zir Fak Basımevi, 249-253

Ekici H., Şimşek Ö. , Arıkan Ş. , Eren M. , Güner B., 2015Comparing levels of certain heavy metals and minerals and antioxidative metabolism in cows raised near and away from highways Turk $\mathbf{J}$ Vet Anim Sci 39: 322-327

Koyuncu N., Uylaser V.,2009 Benzoic Acid and Sorbic Acid Levels in Some Dairy Products Consumed in Turkey, Asian Journal of Chemistry 21, 6 4901-4908
Mutungi C. Passauer L. Onyango C. Jarosa D. Rohma H. 2012 Debranched cassava starch crystallinity determination by Raman spectroscopy: Correlation of features in Raman spectra with X-ray diffraction and 13C CP/MAS NMR spectroscopy, Carbohydrate Polymers 87, 1, 598-606.

Öztürk B. E., Kaptan B., Şimşek O., 2012 Determination of Some Heavy Metals Level in Kashar Cheese Produced in Thrace Region, Journal of Tekirdag Agncultural Faculty 9 (3) 79-83

P. H. R. Júnior, K. de Sá Oliveira ve ark., 2016 FT-Raman and chemometric tools for rapid determination of quality parameters in milk powder: Classification of samples for the presence of lactose and fraud detection by addition of maltodextrin, Food Chemistry 196 584-588

Tekinşen OC.,Tekinşen KK.,2005. Süt ve Süt Ürünleri: Temel Bilgiler, Teknoloji , Kalite Kontrolü. Selçuk Üniversitesi,basımevi,Konya.

www.tulumpeyniri.gen.tr/turk-gidakodeksi-peynir-tebligi/ adresinden erişildi. 